\title{
Bupivacaine in alginate and chitosan nanoparticles: an in vivo evaluation of efficacy, pharmacokinetics, and local toxicity
}

This article was published in the following Dove Press journal: Journal of Pain Research

\section{Cíntia Maria Saia Cereda,' Daniel Sebbe Mecatti, ${ }^{2}$ Juliana Zampoli Boava Papini,' Diego Valério Bueno, ${ }^{2}$ Michelle Franz- Montan, ${ }^{3}$ Thalita Rocha, ${ }^{2}$ José Pedrazzoli Júnior, ${ }^{2}$ Eneida de Paula, ${ }^{4}$ Daniele Ribeiro de Araújo, ${ }^{5}$ Renato Grillo, ${ }^{6}$ Leonardo Fernandes Fraceto, ${ }^{7}$ Silvana Aparecida Calafatti, ${ }^{2}$ Giovana Radomille Tofoli'}

'Institute and Research Center São Leopoldo Mandic, Campinas, São Paulo, Brazil; ${ }^{2}$ UNIFAG, São Francisco University, Bragança Paulista, São Paulo, Brazil; ${ }^{3}$ Department of Physiological Sciences, University of Campinas, Piracicaba, São Paulo, Brazil; ' ${ }^{4}$ Department of Biochemistry and Tissue Biology, University of Campinas, Campinas, São Paulo, Brazil; ${ }^{5}$ Human and Natural Science Centre, Federal University of $A B C$, Santo André, São Paulo, Brazil; ${ }^{6}$ Department of Physics and Chemistry, School of Engineering, São Paulo State University (UNESP), Ilha Solteira, São Paulo, Brazil; ' Department of Environmental Engineering, São Paulo State University (UNESP), Sorocaba, São Paulo, Brazil
Correspondence Giovana Radomille Tofoli Institute and Research Center São Leopoldo Mandic, Rua José Rocha Junqueira 13 , 13045-75, Campinas, São Paulo, Brazil Email giovana.tofoli@sImandic.edu.br

\begin{abstract}
Objective: This study reports a preclinical evaluation of an alginate/chitosan nanoparticle formulation containing NovaBupi ${ }^{\circledR}$, a racemic bupivacaine (BVC) containing $25 \%$ dextrobupivacaine and $75 \%$ levobupivacaine.

Methods: New Zealand White rabbits $(n=6)$ received intraoral or intrathecal injections of BVC $0.5 \%$ or BVC $0.5 \%$-loaded alginate-chitosan nanoparticles $\left(\mathrm{BVC}_{\mathrm{ALG}}\right)$. BVC plasma levels and pharmacokinetic parameters were determined in blood samples of these rabbits. An infraorbital nerve blockade was performed in male Wistar rats $(n=7)$ with the same formulations and the vehicle $\left(\mathrm{NP}_{\mathrm{ALG}}\right)$. Histological evaluation of local toxicity after 6 hours and 24 hours of the treatments was performed in rats' $(\mathrm{n}=6)$ oral tissues.
\end{abstract}

Results: No statistically significant difference was observed between plasma concentrations and pharmacokinetic parameters $(p>0.05)$ after intraoral injections. However, after intrathecal injection $\mathrm{BVC}_{\mathrm{ALG}}$ changed approximately three times the values of volume of distribution and area under the curve $\left(\mathrm{AUC}_{0-\mathrm{t}} ; p<0.05\right)$. The total analgesic effect of $\mathrm{BVC}$ after infraorbital nerve blockade was improved by 1.4 -fold $(p<0.001)$ with $\mathrm{BVC}_{\mathrm{ALG}}$. $\mathrm{BVC}$ and $\mathrm{BVC}_{\mathrm{ALG}}$ did not induce significant local inflammatory reaction.

Conclusion: The encapsulation of BVC prolongs the local anesthetic effect after infraorbital nerve blockade and altered the pharmacokinetics after intrathecal injection.

Keywords: local anesthetics, bupivacaine, polymeric nanoparticle, drug delivery, preclinical study

\section{Introduction}

Local anesthetics (LAs) are used for anesthesia and analgesia during trans- and postoperative periods or for management of acute and chronic pain conditions. ${ }^{1}$ In contact with the nerve fiber trunk, these agents bind to specific sites of sodium channels of the nerve membrane and promote a reversible interruption of the nerve impulses due to decreased permeability to sodium ions. ${ }^{2,3}$

Bupivacaine (BVC) is a long-acting LA that belongs to the amino-amide class and is widely used during surgical procedures and for postoperative pain. Due to its chemical structure, BVC presents a stereocenter and has two isomers, dextrobupivacaine $(\mathrm{R}(+) \mathrm{BVC})$ and levobupivacaine (LBVC; $\mathrm{S}(-) \mathrm{BVC}) .{ }^{4}$ The physicochemical properties of the two isomers molecules are the same, but these molecules can present different behaviors in their affinity for either the site of action or the sites involved in the generation of side effects. The biologic effects of enantiomers differ, both quantitatively and qualitatively, due to receptor configuration. ${ }^{5}$

$\mathrm{R}(+) \mathrm{BVC}$ produces greater tonic and phasic block of sodium channels than $\mathrm{S}(-)$ BVC, two and three times, respectively. ${ }^{6}$ The affinity of R- and S-isomers of BVC is 
different for ion channels of sodium, potassium, and calcium, and this results in a significant reduction of toxicity in central nervous and cardiac systems of the $\mathrm{S}(-) \mathrm{BVC}^{5-9}$

Therefore, $\mathrm{S}(-) \mathrm{BVC}$ is a long-acting anesthetic with less risk of cardiotoxicity and neurotoxicity compared with BVC. ${ }^{6}$ Also, LBVC has a similar clinical profile compared to BVC but presented lower potency for motor blockade, which is a major advantage in regional anesthesia and analgesia. ${ }^{9}$

Thus, LBVC has become a good option for prolonged regional anesthesia and investigations on stereoselectivity have allowed for changes in BVC stereoisomers concentrations in LA formulations. In this context, an LA formulation with $25 \% \mathrm{R}(+) \mathrm{BVC}$ and $75 \% \mathrm{~S}(-) \mathrm{BVC}$ was released in Brazil. This formulation, called NovaBupi ${ }^{\circledR}$ (S75-R25), improved the anesthetic profile compared to LBVC and increased its safety margin. ${ }^{4,10,11}$

Despite these advantages, all LA molecules present low molecular weight and consequently rapid systemic absorption. As an outcome, their anesthetic effect presents short duration and the risk of systemic toxicity precludes the use of high bolus doses. ${ }^{2}$ High LA plasma concentration may lead to a progressive range of neurological and cardiac complications with potentially devastating effects. ${ }^{12}$

The use of LA drug delivery systems, such as liposomes, polymeric nanoparticles, or cyclodextrins as carriers, has improved the therapeutic effects of these agents. These systems are able to prolong LA action, decrease plasma levels, or allow the use of lower LA doses to achieve equivalent analgesia to commercially available formulations. ${ }^{2,4,13-15}$

A carrier system for BVC (enantiomeric mixture S75R25) was developed by Grillo et al. ${ }^{4}$ This system used alginate/chitosan nanoparticles with $\mathrm{BVC}\left(0.5 \%\right.$; $\left.\mathrm{BVC}_{\mathrm{ALG}}\right)$. The amount of BVC associated in the nanoparticles was $\sim 76 \%$. In vitro release kinetics showed that the complete release $(100 \%)$ of BVC in solution occurred after 350 minutes, while complete release of BVC present in the nanoparticles required $>900$ minutes. The formulation was tested in 3T3-fibroblasts culture cells and presented low cytotoxicity. $\mathrm{BVC}_{\mathrm{ALG}}$ formulation significantly reduced the cytotoxicity when compared with plain BVC at $20 \mu \mathrm{M}$. BVC ${ }_{\mathrm{ALG}}$ was also tested in vivo after the sciatic nerve blockade model and the formulation promoted an increase in the intensity and in the duration of motor and sensory blockades; also, this formulation enhanced the differential nerve blockade.

Previous data obtained by Grillo et $\mathrm{al}^{4}$ supported the advantages of this new formulation of $\mathrm{BVC}_{\mathrm{ALG}}$ and perspectives for its clinical future use. Nevertheless, before the clinical use of this formulation, it is necessary to determine its pharmacokinetic, efficacy, and local toxicity profile in animal models. This evaluation is important for fundamental information of this new sustained-release pharmaceutical formulation, such as $\mathrm{BVC}_{\mathrm{ALG}}$. Thus, the aims of this study were to determine plasma levels, efficacy, and local toxicity induced by this new formulation of $\mathrm{BVC}_{\mathrm{ALG}}$ in rats and rabbits, looking forward to its clinical use in dentistry and medicine.

\section{Methods}

\section{Chemicals and reagents}

The commercial anesthetic solution used in this study was plain $0.5 \%$ BVC (NovaBupi ${ }^{\circledR}$; Cristália Ind Farm Ltda, Itapira, São Paulo, Brazil; batch no 10129262). BVC (S75-R25) salt was donated by Cristália Ind Farm Ltda. Alginate, polyvinyl alcohol, and chitosan were obtained from Sigma-Aldrich Co (St Louis, MO, USA). All other reagents were of analytical grade and deionized water was obtained from an ultrapure water system (Millipore Milli-Q system; Milford, MA, USA).

\section{$B_{A V C_{A L G}}$ formulation}

$\mathrm{BVC}_{\mathrm{ALG}}$ formulation used in this study was identical to that described previously and exhibited the same in vitro characteristics as described by Grillo et al. ${ }^{4} \mathrm{~A}$ solution of sodium alginate $(0.063 \% \mathrm{~m} / \mathrm{v})$ containing $0.5 \%$ BVC (S75-R25) was prepared; $7.5 \mathrm{~mL}$ calcium chloride $(18 \mathrm{mM})$ was slowly added in 60 minutes under mechanical agitation. Chitosan solution $(0.07 \%, \mathrm{~m} / \mathrm{v})$ was then added over 90 minutes with a peristaltic pump with controlled flow. After preparation, the nanoparticles were stored in an amber flask for later usage.

\section{Animals and in vivo studies: infraorbital nerve blockade, local toxicity, and pharmacokinetics}

The animals used in this study were male Wistar rats (Unib: WH) (250-350 g) and New Zealand White rabbits $(2.5-3.0 \mathrm{~kg})$. The experimental protocol was approved by the Institutional Committee for Ethics in Animal Research of São Francisco University (protocol \#001.09.10) which follows the recommendations of the Guide for the Care and Use of Laboratory Animals. Animals were housed five per cage (rats) or one per cage (rabbits) and received water and food ad libitum with a $12: 12$ hour light-dark cycle, at $23^{\circ} \mathrm{C} \pm 2^{\circ} \mathrm{C}$.

\section{Pharmacokinetic study}

New Zealand White rabbits were randomly divided into four groups $(n=6)$, which received a submucosal intraoral $(1 \mathrm{~mL})$ or intrathecal $(0.2 \mathrm{~mL})$ injection of the following treatments: 
BVC plain (BVC) or BVC with nanoparticles $\left(\mathrm{BVC}_{\mathrm{ALG}}\right)$. Doses for intraoral and intrathecal injections were 2 and $0.4 \mathrm{mg} \cdot \mathrm{kg}^{-1}$, respectively.

General anesthesia was achieved with $\alpha$-chloralose $\left(50 \mathrm{mg} \cdot \mathrm{kg}^{-1}\right)$ and urethane $\left(1 \mathrm{~g} \cdot \mathrm{kg}^{-1}\right)$ before the injections and an intravascular catheter was inserted in the ear vein of the rabbits. Blood samples $(1 \mathrm{~mL})$ were collected via a heparinized cannula pre-dose ( 0 minutes) and 15, 30, 45, 60, $90,120,180,240,300,360,420,480$, and 540 minutes after the injection of formulations. These intervals were defined to obtain 11 samples between the baseline ( 0 minutes) and approximately four times the $t^{1 / 2}$ (half-life time) of BVC ( 136 minutes). ${ }^{16}$ Immediately after each blood collection, plasma was separated and stored at $-70^{\circ} \mathrm{C}$ until analysis.

\section{Liquid chromatography-tandem mass spectrometry (LC-MS/MS) assay: apparatus and chromatographic conditions}

A Shimadzu LC 20 AD system (Shimadzu Corporation, Kyoto, Japan) coupled with a Micromass Quattro LC $®$ triple stage quadrupole mass spectrometer (LC-MS/MS), equipped with an atmospheric pressure ionization electrospray source, was used to determine the BVC plasma levels. All separations were carried out on a Polaris C18 column $(50 \times 2 \mathrm{~mm}$ id, $5 \mu \mathrm{m}$ particle size). The mobile phase was $80 \%$ acetonitrile and $20 \%$ water with $0.1 \%$ formic acid $(\mathrm{pH}=3.0)$. The total run time was 2.5 minutes, retention time for BVC was 0.72 minutes. The mass spectrometer was run in the positive mode (ES+) and set for multiple reaction monitoring (MRM). The full-scan single-mass spectrum and the daughter ion-mass spectrum for BVC and ropivacaine (internal standard [IS]) were $(\mathrm{m} / \mathrm{z}) 289.3>140.1$ and 275.3>125.9, respectively. Data were integrated using the MassLynx 4.1 ${ }^{\mathrm{TM}}$ (Waters Corporation, Milford, MA, USA) software.

To validate the method, quality control (QC) samples $\left(90.0,45.0\right.$, and $\left.0.9 \mathrm{ng} \cdot \mathrm{mL}^{-1}\right)$ were prepared by mixing drugfree plasma with appropriate volumes of working solutions.

\section{Sample preparation}

The frozen plasma samples $(50.0 \mu \mathrm{L})$ were thawed at room temperature, followed by the addition of $50 \mu \mathrm{L}$ of IS work solution (ropivacaine $10.0 \mu \mathrm{g} \cdot \mathrm{mL}^{-1}$ ). The samples were previously vortexed for 2 minutes and $1000 \mu \mathrm{L}$ of hexane/ethyl acetate $(1: 1 ; \mathrm{V} / \mathrm{V})$ were added and then vortexed for $5 \mathrm{~min}$ utes and centrifuged at $1200 \times g$, for 5 minutes at $-4^{\circ} \mathrm{C}$. The organic liquid $(0.8 \mu \mathrm{L})$ layers were transferred to microtubes and the samples were dried under nitrogen flow. After solvent evaporation, samples were reconstituted in $50 \mu \mathrm{L}$ mobile phase, vortexed for 1 minute, and $50 \mu \mathrm{L}$ were transferred to LC-MS/MS system vials, for further injection $(5.0 \mu \mathrm{L})$.

Precision and accuracy of the analytical method were controlled by calculating the intra-batch and inter-batch variation at three concentrations of QC in five replicates $(n=5)$. Three calibration curves were plotted as the peak area ratio versus BVC concentration in the range of $0.3-120.0 \mathrm{ng} \cdot \mathrm{mL}^{-1}$. The limit of quantification (LQ) was defined as the lowest concentration at which precision and accuracy were within $20 \%$ of the true value.

\section{Infraorbital nerve blockade}

Rat infraorbital nerve blockade was performed as previously described. ${ }^{17,18}$ The antinociceptive effect was assessed by observation of the aversive response to the rat upper lip pinching, according to the scores: 0 (aversive response) or 1 (no aversive response). The observation was performed by an individual that was blind to the injected formulations. The tested formulations $\left(\mathrm{BVC}, \mathrm{BVC}_{\mathrm{ALG}}\right.$, and the vehicle alginate and chitosan nanoparticles $\left.\left[\mathrm{NP}_{\mathrm{ALG}}\right]\right)$ were injected into the infraorbital notch $(0.1 \mathrm{~mL})$, situated above a gap between the posterior four molars and the anterior incisor, after the animals had been lightly anesthetized with thiopental (25 $\mathrm{mg} \cdot \mathrm{kg}^{-1}$ ) by the intraperitoneal route. $\mathrm{NP}_{\mathrm{ALG}}$ was prepared in the same way as described earlier in the section " $\mathrm{BVC}_{\mathrm{ALG}}$ formulation" without the addition of BVC.

The degree of sedation did not interfere with the generalized aversive response to the upper lip artery forceps pinching. Each formulation was injected unilaterally into the right side, and the intact left side served as a control for each animal. The same investigator performed all experiments. The rats were tested every 5 minutes until the animals presented the first aversive sign in the injected side. The efficacy of the infraorbital nerve block was analyzed by the time for sensory function recovery and the total LA effect. LA effect was estimated by the area under the time curve (AUC) expressed as score/hour. ${ }^{17,18}$

\section{Local toxicity and histological evaluation}

Male Wistar rats $(n=3)$ received slightly general anesthesia induced by an intraperitoneal injection of sodium thiopental solution (40 $\left.\mathrm{mg} \cdot \mathrm{kg}^{-1}\right)$, before the administration of the LA formulations. The animals were divided in three groups and received $0.1 \mathrm{~mL}$ in the oral mucosa of the upper right first molar of one of the following formulations: 1) BVC; 2) $\mathrm{BVC}_{\mathrm{ALG}}$; or 3) $\mathrm{NP}_{\mathrm{ALG}}$. The same amount of saline solution $(\mathrm{NaCl} 0.9 \%)$ was administered in the left side as control. ${ }^{17,18}$ 
Animals were sacrificed under anesthesia (urethane $1 \mathrm{~g} \cdot \mathrm{kg}^{-1}$ and $\alpha$-chloralose $50 \mathrm{mg} \cdot \mathrm{kg}^{-1}$ ) 6 and 24 hours after treatment and the maxilla bones along with soft tissues were removed.

The samples from each animal were prepared to obtain five cross-sections ( $6 \mu \mathrm{m}$ thick, $40 \mu \mathrm{m}$ deep) stained with $\mathrm{H} \& \mathrm{E}$ in the same way as described by de Araujo et al. ${ }^{18}$ The cross-sections were qualitatively analyzed with a score in order to evaluate the intensity of the leucocitary infiltration and/or any area of necrosis. The score of the local tissue inflammation was defined based on the following descriptions: 1) no infiltrate; 2) minimal infiltrate; 3) mild infiltrate; 4) severe infiltrate; and 5) severe infiltrate with necrosis areas. ${ }^{19,20}$ The cross-sections were codified by a third subject, and two subjects blindly evaluated all the images according to the qualitative score previously described.

\section{Statistical analysis}

The plasma concentrations of BVC were analyzed by an unpaired $t$-test considering each period of time separately. Pharmacokinetic parameters (maximum plasma concentration, Cmax; time to reach maximum concentration, Tmax; AUC; half-life time, $t \frac{1}{2}$; volume of distribution, $\mathrm{Vd}$; clearance, $\mathrm{Cl}$; mean residence time) were calculated using WinNonlin software (WinNonlin version 5.3; Pharsight Corporation, Mountain View, CA, USA). The pharmacokinetic data were also submitted for statistical analysis with unpaired $t$-test ( $\alpha=0.05)$. The results obtained in each time interval (6 and 24 hours) were compared considering each group and considering the control side. Data were analyzed with the Kruskal-Wallis test considering each group (intergroup analysis). The tissue reaction was also analyzed by Wilcoxon paired test considering the treated and control sides (intragroup analysis). Infraorbital nerve blockade data (time for recovery and AUC) were analyzed by the Mann-Whitney test and expressed as medians (minimum and maximum limits). The level of significance was set at $5 \%$.

\section{Results}

Analysis using MRM function was highly selective since no interfering compounds and significant ion suppression from endogenous substances were observed at the retention times for BVC and IS. The intra-batch accuracy presented values from $99.25 \%$ to $106.00 \%$ and precision was in the range of $0.93 \%-5.77 \%$. The inter-batch accuracy and precision were calculated to be from $99.52 \%$ to $102.16 \%$ and from $1.29 \%$ to $4.46 \%$, respectively. The calibration curve for BVC showed a good response over the range of $0.3-120.0 \mathrm{ng} \cdot \mathrm{mL}^{-1}$. The relative error of the mean of measured concentrations ranged from $0.30 \%$ to $1.16 \%$. The determination coefficients $\left(r^{2}\right)$ were $>0.99$ for all curves. In addition, the LQ for BVC was $0.3 \mathrm{ng} \cdot \mathrm{mL}^{-1}$. The described method has proven to be rapid and effective to accurately follow this BVC formulations' pharmacokinetics.

Figure 1 shows the graph of mean plasma concentrations versus time after the intraoral (Figure 1A) and intrathecal (Figure 1B) injections of BVC and $\mathrm{BVC}_{\mathrm{ALG}}$. No statistically significant difference was observed between plasma concentrations of the two formulations for all periods of time $(p>0.05)$ after intraoral injection (Figure 1A). After intrathecal administration (Figure 1B), during 30-180 minutes $\mathrm{BVC}_{\mathrm{ALG}}$ presented lower plasma concentrations when compared with BVC $(p<0.05)$. Two hundred forty minutes
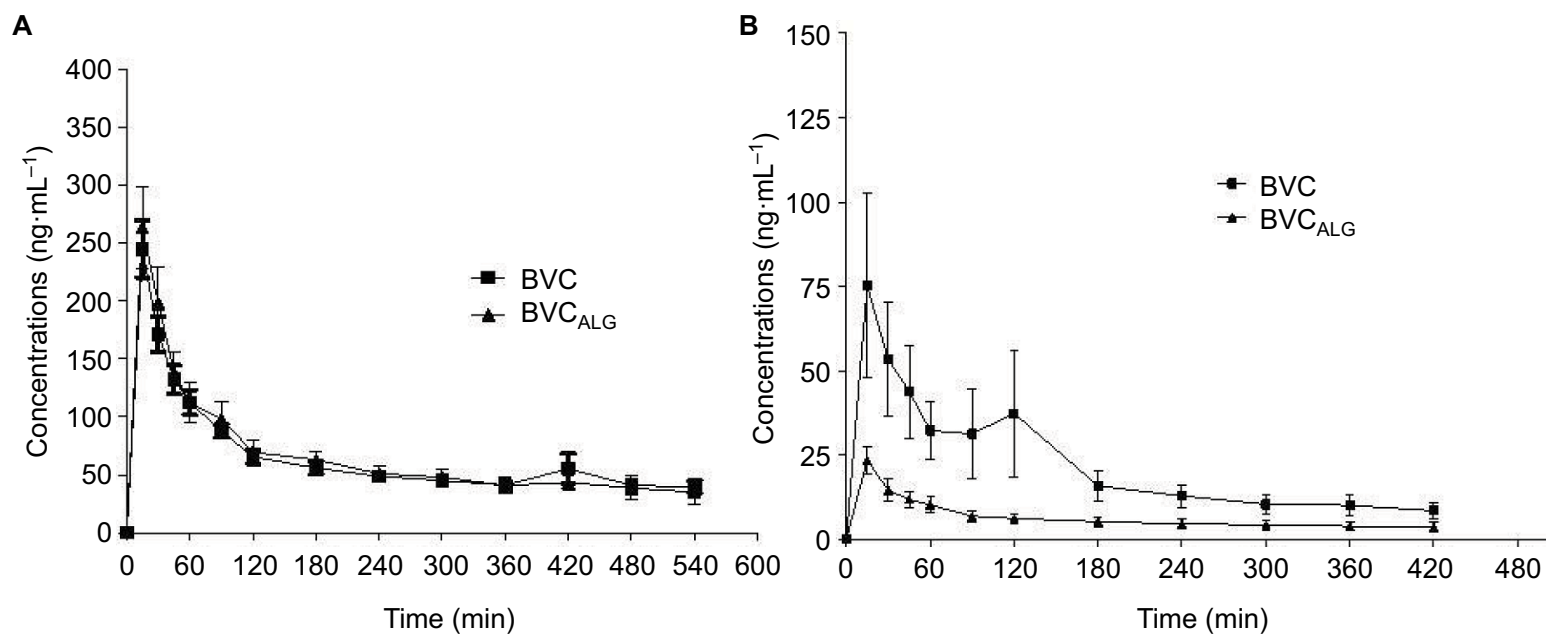

Figure I Graph of mean plasma concentration versus time after the intraoral (A) or intrathecal (B) injections of BVC formulations in rabbits. Note: Values are expressed as mean \pm SD.

Abbreviations: BVC, bupivacaine; $\mathrm{BVC}_{\mathrm{ALG}}, 0.5 \%$ bupivacaine-loaded alginate-chitosan nanoparticles. 
after the injections there were no differences between the two BVC formulations after intrathecal administration.

Table 1 reports the mean $( \pm S D)$ values of the pharmacokinetic parameters obtained after intraoral and intrathecal injections of the tested formulations. No statistically significant difference was observed between the two formulations $(p>0.05)$ for all pharmacokinetic parameters after intraoral injection. Intrathecal injection of $\mathrm{BVC}_{\mathrm{ALG}}$ changed approximately three times the values of $\mathrm{Vd}$ and $\mathrm{AUC}_{0-\mathrm{t}}(p<0.05)$. Despite the absence of significant differences $(p>0.05), \mathrm{Cmax}$ and $\mathrm{AUC}_{0-\infty}$ were three times lower for $\mathrm{BVC}_{\mathrm{ALG}}$ and $t^{1 / 2}$ and $\mathrm{Cl}$ presented lower values for $\mathrm{BVC}$.

The $\mathrm{BVC}_{\mathrm{ALG}}$ increased significantly $(p<0.001)$ the duration of sensory blockade, since the intensity of the total analgesic effect was improved (1.4-fold) when compared with BVC plain solution. Figure 2 shows these results expressed as a percentage of animals with analgesia. Table 2 summarizes the total analgesic effect (expressed as AUC) and the times for recovery, obtained with the tested formulations. $\mathrm{NP}_{\mathrm{ALG}}$, used as control, presented no effect.

Considering the intragroup analysis (right - treated and left - control sides) after 6 hours, only BVC induced higher inflammatory reaction scores when compared with saline $(p<0.05)$. After 24 hours of treatment, $\mathrm{NP}_{\mathrm{ALG}}$ induced more intense inflammatory reaction when compared with $\mathrm{BVC}$ and $\mathrm{BVC}_{\mathrm{ALG}}(p<0.05)$. Table 3 demonstrates the median values of the scores obtained after 6 and 24 hours of treatments and their controls. Figures 3 and 4 show transverse sections of the maxilla bones and their surrounding soft tissues after 6 and 24 hours of the injections of the tested formulations, respectively.

\section{Discussion}

Several studies evaluated the effect of drug delivery systems in the pharmacokinetics of BVC used by diverse routes of administrations. Usually, the use of drug delivery systems with LA solutions alters its pharmacokinetic profile and decreases the rate of systemic absorption and peak plasma concentration. ${ }^{21-23}$ These previous studies showed a decrease

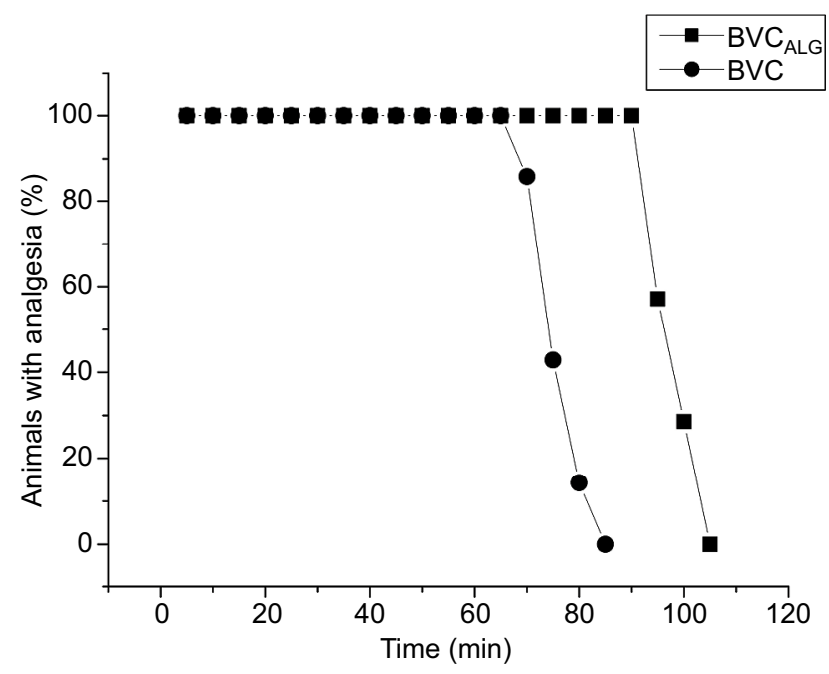

Figure 2 Time-course (minutes) showing the percentage of animals with analgesia after treatment with $0.5 \%$ BVC plain solution or encapsulated into alginate-chitosan nanoparticles $\left(\mathrm{BVC}_{\mathrm{ALG}}\right)$ as evaluated by the infraorbital nerve blockade test in rats ( $n=7 /$ group).

Abbreviations: $\mathrm{BVC}$, bupivacaine; $\mathrm{BVC}_{\mathrm{ALG}}, 0.5 \%$ bupivacaine-loaded alginatechitosan nanoparticles.

in systemic LA concentration despite the type of carrier associated with BVC.

In our study, we used rabbits for the pharmacokinetic studies, especially because these animals present a higher volume of blood and easy ways to collect it when compared with rats. ${ }^{24}$ Their ear vein can be easily cannulated with a simple puncture technique to collect multiple plasma samples. The encapsulation of $\mathrm{BVC}$ in $\mathrm{NP}_{\mathrm{ALG}}$ was not capable of altering the pharmacokinetic profile after intraoral injection

Table I Pharmacokinetic parameters after intraoral and intrathecal injections of BVC or BVC ${ }_{\mathrm{ALG}}$ in rabbits

\begin{tabular}{|c|c|c|c|c|}
\hline \multirow{2}{*}{$\begin{array}{l}\text { Pharmacokinetic parameters } \\
\text { (mean } \pm \text { SD) }\end{array}$} & \multicolumn{2}{|l|}{ Intraoral } & \multicolumn{2}{|l|}{ Intrathecal } \\
\hline & BVC & BVC $_{\text {ALG }}$ & BVC & BVC $_{\text {ALG }}$ \\
\hline $\mathrm{Cmax}\left(\mathrm{ng} \cdot \mathrm{mL}^{-1}\right)$ & $244.95 \pm 60.22$ & $263.47 \pm 86.28$ & $88.91 \pm 70.05$ & $23.4 I \pm 8.32$ \\
\hline $\operatorname{Tmax}(\min )$ & $17.50 \pm 6.12$ & $15.00 \pm 0.00$ & $0.58 \pm 0.70$ & $0.25 \pm 0.00$ \\
\hline$A \cup C_{0-t}\left(n g-h \mathrm{~mL}^{-1}\right)$ & $1100.72 \pm 172.27$ & $1172.99 \pm 340.14$ & $152.17 \pm 100.46 *$ & $43.79 \pm 22.67$ \\
\hline $\mathrm{AUC}_{0-\infty}\left(\mathrm{ng}-\mathrm{h} \mathrm{mL^{-1 }}\right)$ & $1610.83 \pm 402.47$ & $|49| .4 \mid \pm 478.95$ & $217.70 \pm 126.65$ & $88.86 \pm 62.48$ \\
\hline$t^{1 / 2}$ beta $(h)$ & $6.19 \pm 1.52$ & $4.74 \pm 2.08$ & $5.45 \pm 2.53$ & $7.29 \pm 2.82$ \\
\hline $\operatorname{Vd}(\mathrm{L})$ & $28.43 \pm 7.68$ & $24.45 \pm 10.66$ & $54.02 \pm 48.04 *$ & $|4| .47 \pm 43.98$ \\
\hline $\mathrm{Cl}\left(\mathrm{L} \cdot \mathrm{h}^{-1}\right)$ & $3.24 \pm 0.69$ & $3.86 \pm 1.98$ & $6.31 \pm 3.87$ & $17.74 \pm 14.86$ \\
\hline MRT (h) & $4.55 \pm 0.39$ & $4.48 \pm 0.57$ & $2.40 \pm 0.31$ & $2.46 \pm 0.37$ \\
\hline
\end{tabular}

Notes: Data are expressed as mean $\left( \pm\right.$ SD) $\left(n=6 /\right.$ group). Statistical analysis: ANOVA/Kruskal-Wallis; $* B V C \times B V C_{A L G} ; p<0.05$.

Abbreviations: $\mathrm{BVC}$, bupivacaine; $\mathrm{BVC}_{\mathrm{ALG}}, 0.5 \%$ bupivacaine-loaded alginate-chitosan nanoparticles; $\mathrm{MRT}$, mean residence time; $\mathrm{Cl}$, clearance; $\mathrm{Vd}$, volume of distribution; $t^{1} / 2$, half-life time; AUC, area under the curve; Tmax, time to reach maximum concentration; Cmax, maximum plasma concentration; ANOVA, analysis of variance. 
in rabbits. Also, these results obtained in vivo were not in accordance with the previous in vitro evaluation performed by Grillo et al. ${ }^{4}$ These authors assessed the release profile of

Table 2 Total effect of sensory blockade (AUC) and time for recovery for $0.5 \% \mathrm{BVC}$ plain and $\mathrm{BVC}_{\mathrm{ALG}}$ in rats

\begin{tabular}{lll}
\hline Groups & AUC (score/h) & Time for recovery (min) \\
\hline $\mathrm{NP}_{\mathrm{ALG}}$ & 0 & 0 \\
$\mathrm{BVC}$ & $67.5(62.5-77.5)$ & $75(70-85)$ \\
$\mathrm{BVC}_{\text {ALG }}$ & $92.5(87.5-97.5)^{* * *}$ & $100(95-105)^{* * *}$ \\
\hline
\end{tabular}

Notes: Statistical analysis: Mann-Whitney test, ${ }^{* * *} p<0.001$ BVC versus $B C_{\text {ALG }}$. Data are expressed as median (minimum-maximum) ( $n=7 /$ group).

Abbreviations: $\mathrm{BVC}$, bupivacaine; $\mathrm{BVC}_{\mathrm{ALG}}, 0.5 \%$ bupivacaine-loaded alginatechitosan nanoparticles; $\mathrm{AUC}$, area under the curve; $\mathrm{NP}_{\mathrm{ALG}}$, alginate/chitosan nanoparticle.
BVC from the nanoparticles in a two-compartment system separated with a cellulose membrane maintained under sink conditions with light agitation. They observed modification of the release profile of BVC when associated with the nanoparticles, the complete transfer of BVC in solution after 350 minutes, while the release of BVC in nanoparticles persisted for about 10 hours. This modification of the release profile in the presence of the nanoparticles is indicative of association, with release being dependent on diffusion through the system, erosion, or other phenomena, before permeation of the pharmaceutical through the membrane separating the donator and receptor compartments. One aspect that must be considered is that the absorption of LA into the circulation

Table 3 Median (minimum-maximum limits) of the inflammatory scores for all treatments and their controls 6 and 24 hours after the treatment $(0.1 \mathrm{~mL})$ after intraoral administration in rats

\begin{tabular}{|c|c|c|c|c|}
\hline & \multicolumn{2}{|l|}{6 hours } & \multicolumn{2}{|l|}{24 hours } \\
\hline & Test side & Control side & Test side & Control side \\
\hline BVC & $2(I-2) a^{*}$ & $I(I-2)$ & $2(2-3)$ & $I(I-2)$ \\
\hline $\mathrm{BVC}_{\mathrm{ALG}}$ & $I(I-3)$ & $I(I-2)$ & $2(I-3)$ & $I(I-2)$ \\
\hline $\mathrm{NP}_{\mathrm{ALG}}$ & $2(I-3)$ & $I(I-2)$ & $3(3-4) b^{*}, c^{*}, d^{*}$ & $I(I-I)$ \\
\hline
\end{tabular}

Notes: Statistical analysis: Wilcoxon paired test (intragroup): a: BVC vs saline after 6 hours, b: $\mathrm{NP}_{\mathrm{ALG}}$ vs saline after 24 hours, ${ }^{p} p<0.05$. Kruskal-Wallis test (intergroup): c: BVC vs $\mathrm{NP}_{\mathrm{ALG}}$, d: BVC $\mathrm{BLG}_{\mathrm{V}} \mathrm{NS}_{\mathrm{ALG}}$ after 24 hours.

Abbreviations: $\mathrm{BVC}$, bupivacaine; $\mathrm{BVC} \mathrm{ALG}_{\mathrm{AL}}, 0.5 \%$ bupivacaine-loaded alginate-chitosan nanoparticles; $\mathrm{NP}_{\mathrm{ALG}}$, alginate/chitosan nanoparticle.
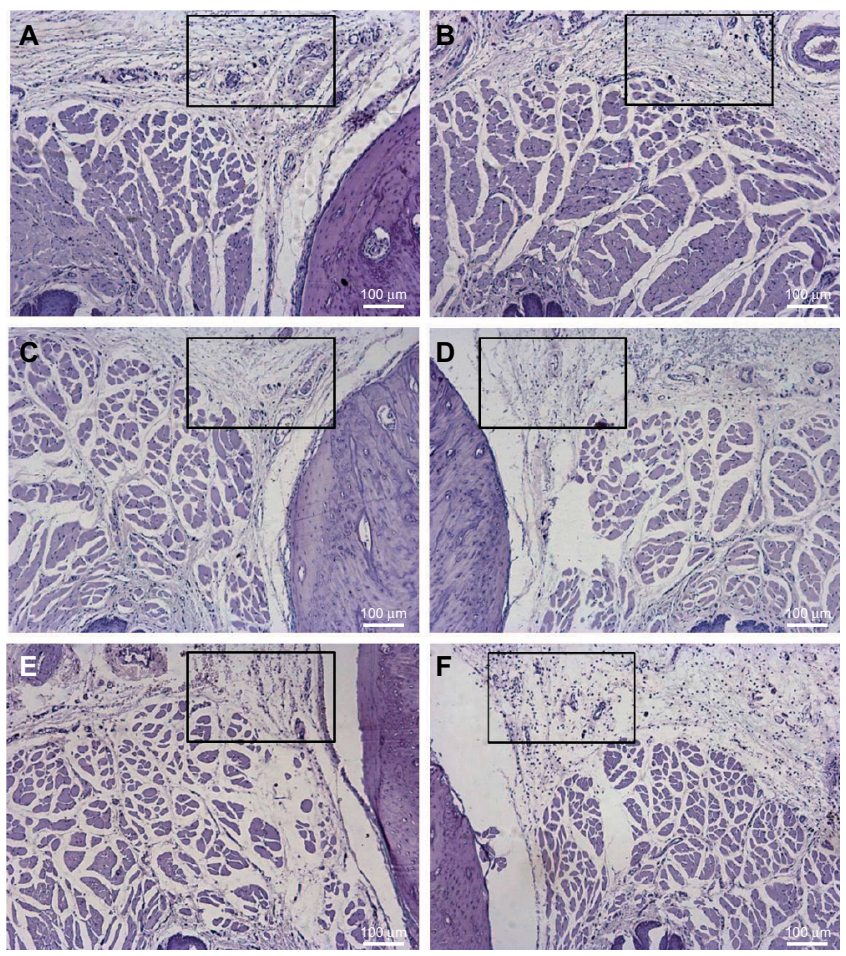

Figure 3 Histological analysis of the upper right first molar oral mucosa in rats 6 hours after local anesthetic administration: (B) BVC; (D) $\mathrm{BVC}_{\mathrm{ALG}}$; (F) $\mathrm{NP}_{\mathrm{ALG}}$. The left side was respectively used as control: (A) control BVC; (C) control $\mathrm{BVC}_{\mathrm{ALG}}$; (E) control $\mathrm{NP}_{\mathrm{ALG}}$

Notes: Observe the local tissue inflammation (rectangle). Scale bar: $100 \mu \mathrm{m}$.

Abbreviations: $\mathrm{BVC}$, bupivacaine; $\mathrm{BVC}_{\mathrm{ALG}}, 0.5 \%$ bupivacaine-loaded alginatechitosan nanoparticles; $\mathrm{NP}_{\mathrm{ALG}}$, alginate/chitosan nanoparticle.
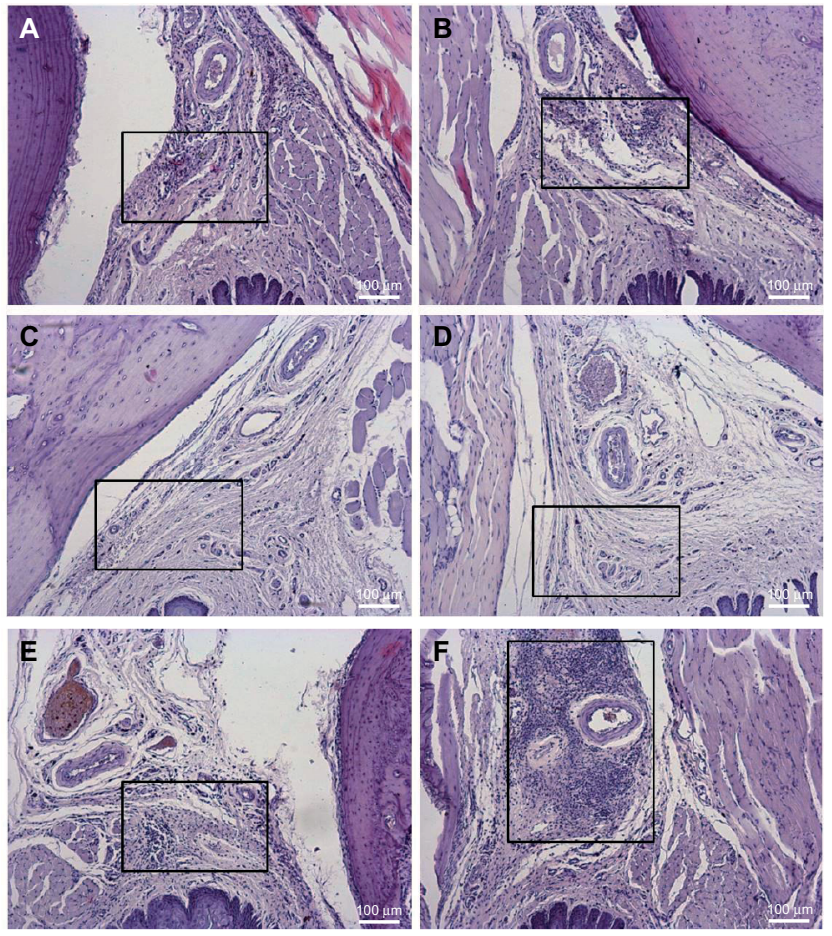

Figure 4 Histological analysis of the upper right first molar oral mucosa in rats 24 hours after local anesthetic administration: (B) BVC; (D) $\mathrm{BVC}_{\mathrm{ALG}}$; (F) $\mathrm{NP}_{\mathrm{ALG}}$. The left side was respectively used as control: (A) control BVC; (C) control $\mathrm{BVC}_{\mathrm{ALG}}$; (E) control $\mathrm{NP}_{\mathrm{ALG}}$

Notes: Observe the local tissue inflammation (rectangle). Scale bar: $100 \mu \mathrm{m}$.

Abbreviations: $\mathrm{BVC}$, bupivacaine; $\mathrm{BVC}_{\mathrm{ALG}}, 0.5 \%$ bupivacaine-loaded alginatechitosan nanoparticles; $\mathrm{NP}_{\mathrm{ALG}}$, alginate/chitosan nanoparticle. 
depends primarily on the vascularity of the site of injection as well as on the structure composition of the surrounding tissues. Moreover, the vasoactive properties of LA may influence the rate of absorption. ${ }^{25}$ In general, LA molecules present rapid systemic absorption as a result of their low molecular weight, mainly in the oral mucosa which is an area with high vascularization. In vitro release tests are commonly used to assess the release profiles of drugs from pharmaceutical formulations, enabling comparison between the absence (free drug) and presence of a carrier. Despite the convenience of such tests, the results obtained may not correspond to the in vivo situation, because after intraoral in vivo administration free LA may be absorbed into the adjacent tissues. ${ }^{2}$

In our study, intrathecal injection of $\mathrm{BVC}_{\mathrm{ALG}}$ promotes slow absorption and $\mathrm{Cl}$ of $\mathrm{BVC}$ from the cerebrospinal fluid (CSF) demonstrated by the lower BVC concentrations in plasma, higher $\mathrm{Vd}$, and lower AUC. We used healthy animals with similar age and weight, intrathecal injections with the same dosage, volume, and only one trained operator for the injection process. Also, the two formulations presented the same baricity and were isobaric in relation to CSF, which means that this factor was not able to alter the absorption or dispersion of BVC on both formulations. ${ }^{26}$ Thus, encapsulation in nanoparticles was the factor responsible for the differences in plasma concentrations of BVC and in the pharmacokinetic parameters after intrathecal injection.

Extended or sustained-release formulations are developed to maintain constant or prolonged concentrations of drugs. An ideal LA extended-release formulation would provide consistent pain control and minimization of adverse events associated with peak drug levels. Distinct formulation technologies might produce varied release and pharmacokinetic profiles and it is possible to observe no lag time in drug absorption (no differences in Tmax) but differences in Cmax and AUC values. ${ }^{27}$ In our study, $\mathrm{BVC}_{\mathrm{ALG}}$ after intrathecal administration presented smaller AUC $\left(\mathrm{AUC}_{0-480}\right)$. We believe that these results were produced by the immense differences observed in the plasma concentrations of BVC with and without the nanoparticles, mainly in the beginning of the curve. Thus, the encapsulation of BVC in these nanoparticles avoided peak plasma concentrations that are usually related to adverse side effects after LA administration. ${ }^{2,13}$ We observed the Vd of BVC after only one extravascular administration and we did not measure the tissue concentration of BVC. Nevertheless, it is expected that a drug extensively bound to tissue will generally have an apparent large $\mathrm{Vd}$, which means that probably $\mathrm{BVC}_{\mathrm{ALG}}$ presented a higher affinity for tissue binding and was not available in the plasma (demonstrated by the lower AUC values).
Usually, the efficacy of LA is demonstrated based on their antinociception activity. However, in animal models, like the one used in our study, this can be difficult to achieve. The degree of pain in rabbits can vary importantly between animals and there are no objective criteria for this evaluation. As a prey species, rabbits may hide their pain by remaining motionless. Thus, rabbits appear to respond to pain in a manner contrary to that of mice or rats, and have little activity or behavior to be assessed. ${ }^{28}$ The lack of pain behavior in rabbits lead to the use of infraorbital nerve blockade to determine the LA formulations efficacy. Also, we selected the infraorbital nerve block to simulate a condition similar to administration of these drugs in the maxillary bone, since our goal was to evaluate a new LA formulation that can be used in both dentistry and medicine. The $\mathrm{BVC}_{\mathrm{ALG}}$ increased the duration of sensory blockade and the intensity of the total analgesic effect was improved by $\sim 1.4$-fold. These results corroborate the findings of Grillo et al, ${ }^{4}$ when the same formulation led to increased analgesia in a mice sciatic nerve blockade. Thus, the new BVC formulations presented a more intense antinociceptive effect after infraorbital nerve blockade.

Evaluation of local toxicity is important to ensure the safeness of new drug delivery systems. The polymeric nanoparticles used in our study are made of natural polymers (alginate and chitosan) that interact to produce a nanoparticle system. ${ }^{4}$ Despite the natural origin of these polymers, our results showed that $\mathrm{NP}_{\mathrm{ALG}}$ produced an intense inflammatory reaction on the oral mucosa after 24 hours (Figure 4F), and this reaction was more intense when compared with BVC and $\mathrm{BVC}_{\mathrm{ALG}}$ (Figure $4 \mathrm{~B}$ and $\mathrm{D}$ ). Previously results from Grillo et $\mathrm{al}^{4}$ also showed that $\mathrm{NP}_{\mathrm{ALG}}$ reduced the cell viability when compared with the negative control group in tests performed with Balb/c fibroblasts (3T3 cells). On the other hand, BVC significantly reduced the local inflammatory reaction evoked by $\mathrm{NP}_{\mathrm{ALG}}$ in our study as seen in the $\mathrm{BVC}_{\mathrm{ALG}}$ group. Our results could be explained by the anti-inflammatory properties of LA in clinical concentrations. ${ }^{29-31}$ LAs possess intrinsic anti-inflammatory properties with mechanisms that are not completely elucidated, but diverge from the sodium channels blockade. Among other properties, LA can reduce the synthesis of interleukin (IL)-1 $\alpha$, IL-1 $\beta$, IL-2, IL-8, tumor necrosis factor- $\alpha$, and interferon- $\Upsilon{ }^{32}$

Preclinical evaluation is an important (and mandatory) part of new formulations development, since the in vitro results may not be replicable during in vivo studies. This study showed a preclinical evaluation of new polymeric alginate-based nanoparticles with BVC for use in dentistry and medicine. The in vivo intraoral pharmacokinetics did not occur such as the 
in vitro release test performed earlier by Grillo et al. ${ }^{4}$ Intrathecal injection of $\mathrm{BVC}_{\mathrm{ALG}}$ promotes slower systemic absorption when compared with BVC. Also, our results showed that this formulation prolonged the LA effect after the infraorbital nerve block and induced tissue reaction comparable to the commercial formulation of BVC. These results encourage the use of this new formulation in dentistry and medicine as a safe and effective option for local anesthesia.

\section{Acknowledgments}

The authors thank Cristália Produtos Quim Farm Ltda (São Paulo, Brazil) for the donation of BVC and FAPESP (2014/14457-5) for the financial support. The authors also thank Mr Edvaldo C Coelho for his contribution in the pharmacokinetics analysis.

\section{Disclosure}

The authors report no conflicts of interest in this work.

\section{References}

1. Shipton EA. New formulations of local anaesthetics - part I. Anesthesiol Res Pract. 2012;2012:546409.

2. de Paula E, Cereda CM, Fraceto LF, et al. Micro and nanosystems for delivering local anesthetics. Expert Opin Drug Deliv. 2012;9:1505-1524.

3. Verlinde M, Hollmann MW, Stevens MF, Hermanns H, Werdehausen R, Lirk P. Local anesthetic-induced neurotoxicity. Int J Mol Sci. 2016;17:339.

4. Grillo R, de Melo NF, de Araujo DR, de Paula E, Rosa AH, Fraceto LF. Polymeric alginate nanoparticles containing the local anesthetic bupivacaine. J Drug Target. 2010;18:688-699.

5. Leone S, Di Cianni S, Casati A, Fanelli G. Pharmacology, toxicology, and clinical use of new long acting local anesthetics, ropivacaine and levobupivacaine. Acta Biomed. 2008;79:92-105.

6. Pacella E, Pacella F, Troisi F, et al. Efficacy and safety of $0.5 \%$ levobupivacaine versus $0.5 \%$ bupivacaine for peribulbar anesthesia. Clin Ophthalmol. 2013;7:927-932.

7. Gulec D, Karsli B, Ertugrul F, Bigat Z, Kayacan N. Intrathecal bupivacaine or levobupivacaine: which should be used for elderly patients? J Int Med Res. 2014;42:376-385.

8. Bozdogan Ozyilkan N, Kocum A, Sener M, et al. Comparison of intrathecal levobupivacaine combined with sufentanil, fentanyl, or placebo for elective caesarean section: a prospective, randomized, double-blind, controlled study. Curr Ther Res Clin Exp. 2013;75:64-70.

9. Misirlioglu K, Sivrikaya G, Hanci A, Yalcinkaya A. Intrathecal lowdose levobupivacaine and bupivacaine combined with fentanyl in a randomised controlled study for caesarean section: blockade characteristics, maternal and neonatal effects. Hippokratia. 2013;17:262-267.

10. Araujo DR, Braga AF, Moraes CM, Fraceto LF, Paula E. Mistura com excesso enantiomérico de 50\% (S75-R25) de bupivacaína complexada com ciclodextrinas e anestesia por via subaracnóidea em ratos [Complexation of $50 \%$ enantiomeric excess (S75-R25) bupivacaine with cyclodextrins and spinal block anesthesia in rats]. Rev Bras Anestesiol. 2006;56:495-506. Portuguese.

11. Araujo DR, Fraceto LF, Braga Ade F, Paula E. Sistemas de liberação controlada com bupivacaína racêmica (S50-R50) e mistura enantiomérica de bupivacaína (S75-R25): efeitos da complexação com ciclodextrinas no bloqueio do nervo ciático em camundongos [Drug-delivery systems for racemic bupivacaine (S50-R50) and bupivacaine enantiomeric mixture (S75-R25): cyclodextrins complexation effects on sciatic nerve blockade in mice]. Rev Bras Anestesiol. 2005;55:316-328. Portuguese.
12. Dillane D, Finucane BT. Local anesthetic systemic toxicity. Can J Anaesth. 2010;57:368-380.

13. Tofoli GR, Cereda CM, Araujo DR, et al. Pharmacokinetic study of liposome-encapsulated and plain mepivacaine formulations injected intra-orally in volunteers. J Pharm Pharmacol. 2012;64:397-403.

14. Seol D, Magnetta MJ, Ramakrishnan PS, et al. Biocompatibility and preclinical feasibility tests of a temperature-sensitive hydrogel for the purpose of surgical wound pain control and cartilage repair. J Biomed Mater Res B Appl Biomater. 2013;101:1508-1515.

15. Barrington JW, Olugbode O, Lovald S, Ong K, Watson H, Emerson RH Jr. Liposomal bupivacaine: a comparative study of more than 1000 total joint arthroplasty cases. Orthop Clin North Am. 2015;46:469-477.

16. Ratajczak-Enselme M, Estebe JP, Rose FX, et al. Effect of epinephrine on epidural, intrathecal and plasma pharmacokinetics of ropivacaine and bupivacaine in sheep. Br J Anaesth. 2007;99:881-890.

17. Cereda CM, Brunetto GB, de Araújo DR, de Paula E. Liposomal formulations of prilocaine, lidocaine and mepivacaine prolong analgesic duration. Can J Anaesth. 2006;53:1092-1097.

18. de Araujo DR, Cereda CM, Brunetto GB, et al. Pharmacological and local toxicity studies of a liposomal formulation for the novel local anaesthetic ropivacaine. J Pharm Pharmacol. 2008;60:1449-1457.

19. Cereda CM, Tófoli GR, de Brito Junior RB, et al. Stability and local toxicity evaluation of a liposomal prilocaine formulation. J Liposome Res. 2008;18:329-339.

20. Tofoli GR, Cereda CM, de Araujo DR, et al. Pharmacokinetic and local toxicity studies of liposome-encapsulated and plain mepivacaine solutions in rats. Drug Deliv. 2010;17:68-76.

21. Le Corre P, Estèbe JP, Clément R, et al. Spray-dryed bupivacaine-loaded microspheres: in vitro evaluation and biopharmaceutics of bupivacaine following brachial plexus administration in sheep. Int J Pharm. 2002;238:191-203.

22. Davidson EM, Barenholz Y, Cohen R, Haroutiunian S, Kagan L, Ginosar Y. High-dose bupivacaine remotely loaded into multivesicular liposomes demonstrates slow drug release without systemic toxic plasma concentrations after subcutaneous administration in humans. Anesth Analg. 2010;110:1018-1023.

23. Bramlett K, Onel E, Viscusi ER, Jones K. A randomized, doubleblind, dose-ranging study comparing wound infiltration of DepoFoam bupivacaine, an extended-release liposomal bupivacaine, to bupivacaine $\mathrm{HCl}$ for postsurgical analgesia in total knee arthroplasty. Knee. 2012;19:530-536.

24. Removal of blood from laboratory mammals and birds. First report of the BVA/FRAME/RSPCA/UFAW Joint Working Group on Refinement. Lab Anim. 1993;27:1-22.

25. Rosenberg PH, Veering BT, Urmey WF. Maximum recommended doses of local anesthetics: a multifactorial concept. Reg Anesth Pain Med. 2004;29:564-575; discussion 524.

26. Malinovsky JM, Charles F, Baudrimont M, et al. Intrathecal ropivacaine in rabbits: pharmacodynamic and neurotoxicologic study. Anesthesiology. 2002;97:429-435.

27. Papini JZB, Cereda CMS, Pedrazzoli Júnior J, Calafatti SA, de Araújo DR, Tofoli GR. Pharmacokinetics and pharmacodynamics evaluation of tramadol in thermoreversible gels. Biomed Res Int. 2017;2017:5954629.

28. Barter LS. Rabbit analgesia. Vet Clin North Am Exot Anim Pract. 2011;14:93-104.

29. Cassuto J, Sinclair R, Bonderovic M. Anti-inflammatory properties of local anesthetics and their present and potential clinical implications. Acta Anaesthesiol Scand. 2006;50:265-282.

30. Votta-Velis EG, Piegeler T, Minshall RD, et al. Regional anaesthesia and cancer metastases: the implication of local anaesthetics. Acta Anaesthesiol Scand. 2013;57:1211-1229.

31. Xuan W, Hankin J, Zhao H, Yao S, Ma D. The potential benefits of the use of regional anesthesia in cancer patients. Int J Cancer. 2015;137: 2774-2784.

32. Grosu I, Lavand'homme P. Continuous regional anesthesia and inflammation: a new target. Minerva Anestesiol. 2015;81:1001-1009. 
The Journal of Pain Research is an international, peer reviewed, open access, online journal that welcomes laboratory and clinical findings in the fields of pain research and the prevention and management of pain. Original research, reviews, symposium reports, hypothesis formation and commentaries are all considered for publication
The manuscript management system is completely online and includes a very quick and fair peer-review system, which is all easy to use. Visit http://www.dovepress.com/testimonials.php to read real quotes from published authors. 